\title{
EVALUASI SETAHUN PELAKSANAAN JAMINAN PERSALINAN DALAM MENURUNKAN ANGKA KEMATIAN IBU DAN BAYI
}

\author{
Mora Claramita *, Fitriana Murriya Ekawati**, Adi Heru Sutomo***
}

\section{Universitas Gadjah Mada, Fakultas Kedokteran, Bagian Pendidikan Kedokteran*, Tim Kedokteran Keluarga $^{* *}$, Bagian Ilmu Kesehatan Masyarakat $* * *$ adiheruhusodo@gmail.com}

\begin{abstract}
Proper insurance system is the first target of millennium development. Indonesian Ministry of Health offers an insurance system for helping reduce infant and maternal mortality rates: The Jampersal. Reproductive health for women and children is the second targets of MDGs . It has been 1 year of Jampersal implementation, therefore it needs to evaluate the effectiveness, especially in a remote area like Ternate in Northern Maluku. The study was conducted by collecting secondary quantitative data and primary qualitative data from 7 Puskesmas in Ternate (out of 8) in August-November 2012. Data were collected from 15 nursery mothers who underwent Jampersal insurance, from 15 midwives, 8 medical doctors and 1 obsgyn specialist from all districts Puskesmas in Ternate. Quantitative data were analyzed by descriptive statistics and qualitative data were analyzed by content analysis. that Jampersal was significantly increased documentation of medical record on mother who delivers the baby in Puskesmas; who were also increased in number. Previously lots of mother delivers at home with traditional birth attendances without proper documentation on medical records. It means that indirectly, Jampersal should have been helping in controling problems on reproductive and child health. However, it is not yet clear that Jampersal actually helps to reduce infant and maternal mortality rate due to many obstacles following the Jampersal implementations.
\end{abstract}

Keywords: The Jampersal, Infant-Maternal-Mortality

\begin{abstract}
Abstrak: Sistem asuransi yang tepat merupakan target pertama dalam perkembangan millennium. Kememterian Kesehatan Indonesia menawarkan sistem asuransi untuk membantu mengurangi angka kematian bayi dan ibu: Jampersal. Kesehatan reproduksi ibu dan anak adalah trget kedua dari MDGs. Jampersal telah berjalan 1 tahun. Oleh karena itu, program ini membutuhkan evaluasi keefektifitasannya, terutama di daerh terpencil seperti Ternate di Maluku Utara. Penelitian ini dilakukan dengan mengmpulkan data kuantitatif sekunder dan data kualitatif primer dari 7 Puskesmas di Ternate (dari 8 Puskesmas) pada Agustus-November 2012. Data dikumpulkan dari 15 ibu di kamar bersalin yang memperoleh asuransi jampersal, 15 bidan, 8 dokter medis dan 1 dokter spesialis kebidanan dari semua puskesmas di kabupaten Ternate. Data kuantitatif dianalisis dengan menggunakan statistic diskriptif dan kualitatif dianalisis dengan menganalisis isi. Jampersal mengalami peningkatan yang signifikan berdasarkan dokumentasi dari rekam medis para ibu yang bersalin di Puskesmas; meningkah dalam jumlah. Sebelumnya, banyak ibu yang bersalin di rimah dengan pertolongan dukun tanpa dokumentasi yang tepat dalam rekam medis. Itu berarti secara tidak langsung, Jampersal telah membantu dalam mengontrol masalah kesehatan reproduksi ibu dan bayi. Namun, belum adanya kejelasan apakah Jampersal benar-benar dapat mengurangi angka kematian ibu dan bayi, bersamaan dengan banyaknya kendala dalam pelaksanaan Jampersal.
\end{abstract}

Kata Kunci: Jampersal, Angka Kematian Ibu dan Bayi

Primary Health Care Now More Than Ever Laporan WHO tahun 2008 ini menyebutkan bahwa pelayanan kesehatan primer adalah di atas segalanya. Pelayanan ini kemudian meliputi banyak aspek kesehatan termasuk upaya penurunan angka kematian ibu dan 
bayi. Jaminan Persalinan (Jampersal) merupakan satu upaya penunjang dalam mencapai tujuan tersebut, yang sangat berpeluang bisa mengkoordinasikan level pelayanan kesehatan yang lebih tinggi untuk menangani masalah sulit yang tidak bisa ditangani di pelayanan primer. Puskesmas terkoordinasi di bawah kepala puskesmas dan dalam urusan pelayanan klinisnya dikoordinasikan oleh dokter (WHO, 2008). Pada petunjuk teknis pelaksanaan Jampersal, puskesmas menempati sisi penting dalam upaya pemberian pelayanan kesehatan sekaligus sebagai gate keeper ketika terdapat kasus sulit yang tidak bisa ditangani di pelayanan kesehatan primer dan memerlukan penanganan lebih lanjut di rumah sakit (Permenkes RI, 2011).

Jampersal adalah jaminan pembiayaan pelayanan persalinan yang meliputi pemeriksaan kehamilan, pertolongan persalinan, pelayanan nifas termasuk pelayanan $\mathrm{KB}$ pasca persalinan dan pelayanan bayi baru lahir yang dilakukan oleh tenaga kesehatan di fasilitas kesehatan. sehingga manfaatnya terbatas dan tidak dimaksudkan untuk melindungi semua masalah kesehatan individu. Dalam teknik pelaksanaannya Jampersal bertujuan menanggung pemeriksaan dasar yang dibutuhkan oleh ibu dan bayi. Pemeriksaan yang ditanggung oleh Jampersal antara terdiri atas : 4 kali pemeriksaan sebelum melahirkan, proses melahirkan, perawatan ibu selama nifas (42 hari) dan perawatan serta imunisasi bayi hingga usia 28 hari (Permenkes RI, 2011).

Jampersal memberi harapan baru tertanganinya permasalahan kesehatan ibu dan bayi, terutama pada penanganan kasus di daerah terpencil seperti Ternate Maluku Utara. Kota Ternate terletak di sebelah barat pulau Halmahera dengan jumlah penduduk di kota Ternate sebanyak 180.671 jiwa. Angka kematian ibu pada wilayah Maluku Utara termasuk Ternate saat ini cukup tinggi, yakni 85 kasus selama tahun 2011. Dengan mengimplementasikan Jampersal, diharapkan angka kematian ibu akan menurun. Sebagai langkah teknis pelaksanaan Jampersal, pengelolaan ibu hamil dilakukan secara lebih komprehensif dengan melibatkan Puskesmas sebagai penyedia pelayanan kesehatan dasar termasuk perawatan ibu hamil dan melahirkan. Jumlah puskesmas di Kota Ternate ber-jumlah 8 Puskesmas, dengan 2 Puskesmas Rawat Inap.

Jampersal meliputi pemeriksaan kehamilan, pertolongan persalinan, pelayanan nifas termasuk pelayanan $\mathrm{KB}$ pasca persalinan dan pelayanan bayi baru lahir yang dilakukan oleh tenaga kesehatan di fasilitas kesehatan. Pelayanan ini diberikan kepada ibu hamil meliputi pemeriksaan sebanyak 4 kali, pemberian tablet besi dan pemantauan lain dalam rangka pemeriksaan antenatal, pertolongan persalinan normal dan persalinan cara lain sesuai indikasi. Pemberian pelayanan setelah persalinan antara lain perawatan nifas, KB setelah persalinan dan pemberian imunisasi kepada bayi hingga usia 28 hari, termasuk komplikasi yang bisa terjadi selama masa masa tersebut.

Dana pelaksanaan program ini berasal dari anggaran belanja negara dan daerah kemudian pelaporannya dimasukkan dalam laporan Jamkesmas. Secara teknis, pelaksanaan Jampersal setara dengan pelayanan kesehatan standar kelas 3. Standar pelayanan dari antenatal care hingga persalinan normal, tenaga kesehatan berhak mendapatkan klaim sebanyak 580 ribu rupiah. Angka ini sering menjadi polemik tersendiri. Evaluasi mengenai Jampersal ini dan target cakupannya belum dilakukan dan menjadi keunikan sendiri ketika hal ini dapat dilakukan oleh institusi pendidikan seperti FK UGM sehingga data yang didapatkan akan lebih akurat dan berkesempatan untuk mendapatkan telaah pemikiran yang lebih kritis.

Di Ternate, pelaksanaan Jampersal ini sudah berjalan hampir 1 tahun sejak November 2011. Evaluasi pelaksanaan Jampersal ini belum dilakukan, terlebih pada efektivitas Puskesmas sebagai tempat pertama pasien mendapatkan pelayanan kesehatan dasar, termasuk kesehatan ibu dan bayi. Minimnya informasi pelayanan kesehatan primer di Kota Ternate, menyebabkan penelitian ini amatlah penting dalam rangka 
mengetahui secara riil pelaksanaan pelayanan kesehatan primer di Kota Ternate.

\section{BAHAN DAN CARA KERJA}

Penelitian ini adalah penelitian deskriptif dengan pendekatan cross sectional dengan menganalisis data pelaksanaan Jampersal berbasis Puskesmas. Penelitian kemudian diperdalam dengan wawancara mendalam terhadap personalia di 7 Puskesmas (dari total sebanyak 8 Puskesmas) di Kota Ternate selama Agustus-November 2012. Satu Puskesmas tidak dikunjungi mengingat saat penelitian dilakukan tengah terjadi letusan Gunung Gamalama. Data sekunder diambil dari data kunjungan ibu hamil, data ibu melahirkan, data ibu menyusui yang mengikuti fasilitas Jampersal di semua puskesmas di Kota Ter-nate di tahun 2012. Populasi penelitian ada-lah tenaga kesehatan di Kota Ternate yang terdiri atas 6 dokter umum, 1 dokter berstrata S2, 1 dokter spesialis Obstetri \& Ginekologi (SPOG) dan 8 bidan. Perlu dijelaskan lagi bahwa peneliti hanya meneliti di tujuh (7) Puskesmas dari 8 Puskesmas yang direnca-nakan karena ada hujan abu dari Gunung Gamalama yang terjadi saat penelitian dila-kukan. Puskesmas yang tidak dikunjungi adalah Puskesmas Batang.

Subjek wawancara mendalam terdiri atas sepuluh ibu hamil di setiap Puskesmas di Kota Ternate di tahun 201 yang memakai kriteria inclusi: dipilih secara acak di setiap Puskesmas,yaitu pasien ketiga dalam setiap kunjungan ke Puskesmas, per harinya, sepuluh ibu menyusui di setiap Puskesmas di Kota Ternate di tahun 2012, dua bidan di setiap puskesmas, satu dokter umum di setiap puskesmas dan satu dokter ahli Kebidanan dan Kandungan (total SPOG di Kota ternate tahun 2012 hanyalah 1 orang saja).

Data dikumpulkan dengan cara peneliti mengumpulkan data sekunder di setiap Puskesmas. Peneliti melakukan wawancara mendalam dengan panduan: "Bagaimana pengalaman Ibu/Bapak dalam mengikuti asuransi Jampersal di tahun ini? Apa yang $\mathrm{Ibu} /$ Bapak rasakan manfaat dari Jampersal? Apa yang menurut Ibu/Bapak masih dapat ditingkatkan lagi dari pelak-sanaan Jampersal berkaitan dengan daerah yang sulit terjangkau pelayanan kesehatan ibu dan anak seperti di wilayah sekitar Ternate?"

Data dianalisis dengan Grounded Theory Methodology untuk mendapatkan kategori-kategori dan kesimpulan hasil akhir yang memadai (Finlay and Ballinger, 2006). "Coding" dilakukan oleh setiap tim peneliti secara berulang sampai seluruh anggota tim peneliti mencapai kesepakatan. Hasil akhir data dari wawancara mendalam dilihat kesesuaiannya atau kecocokannya dengan data sekunder. Kesimpulan akhir diambil dari kedua data di atas.

\section{HASIL}

Cakupan Jampersal yang kami dapatkan sesuai Tabel 1 tidak memuat jumlah total kelahiran maupun ANC karena jumlah yang berkunjung ke Dukun bayi tidak diketahui dengan pasti. Begitu pula apakah ada penurunan AKB dan AKI setelah adanya Jampersal tidak diketahui karena data sebelum adanya Jampersal tidak didapatkan. Dengan demikian hasil nyata dari adanya Jampersal selama satu tahun ini di pulau Ternate adalah: Meningkatkan kunjungan ibu hamil dan ibu menyusui ke Puskesmas, meningkatkan cakupan pelayanan ibu hamil, melahirkan dan menyusui karena adanya dukungan biaya dari pemerintah meningkatkan pencatatan dan pelaporan terkait kasus ANC, Ibu melahirkan dan ibu menyusui. Perlu ditindak lanjuti apakah dari tahun ke tahun manfaat Jampersal tersebut semakin menurunkan AKB dan AKI, terutama karena tidak ada data sebelum adanya Jampersal.

Hasil dari data kualitatif berupa wawancara mendalam dengan ibu menyusui, bidan, dokter dan dokter spesialis, memvalidasi hasil dari metode kuantitatif di atas:

"Senang dengan adanya Jampersal karena

biaya seтиa-sетиa sudah dibantu pemerintah."

(Ibu Menyusui 1)

"Jadi rutin ke Puskesmas."

(Ibu Menyusui 2) 
"Ya, meningkatkan angka kunjungan ibu hamil dan melahirkan di Puskesmas. Kita juga jadi rajin mencatat."

(Bidan 1)

Meskipun demikian beberapa masalah sepertinya masih harus diperhatikan lebih dalam, dan tidak hanya dapat diselesaikan dengan bantuan Jampersal. Berikut kutipan dari beberapa tenaga kesehatan dan ibu menyusui yang kami wawancarai :

"ANC itu ya mereka mau ke Puskesmas. Sayangnya belum tentu melahirkannya juga di sana. Banyak faktor yang mempengaruhi saat akan melahirkan. Misalnya, anak yang pertama dan kedua saja bisa lahir di rumah, mengapa yang ketiga harus di Puskesmas?Banyak yang belum paham akan tujuan Jampersal ini."

(Dokter 1)

"Pada saat akan melahirkan, apabila terjadi kesulitan, sering harus rapat orang sekampung. Mereka tidak paham akan pentingnya waktu pengambilan keputusan. Pada saat dibawa ke rumah sakit ya biasanya sudah terlambat. Jarang yang belum terlambat."

(Dokter Obsgyn)

"Kalau keseluruhan proses ANC, melahirkan, menyusui hanya tanggung jawab Bidan, ya itu sebabnya mengapa sering terjadi masalah. Mengapa tidak melibatkan dokter umum dalam menangani ibu hamil, melahirkan dan menyusui?Padahal dokter-dokter umum ini sudah sering dilatih PONED (Pelayanan Obstetri Emergensi Dasar).Ya Bidan juga dilatih PONED, akan tetapi ilmu kesehatan manusia kan yang lebih menguasai Dokter, sehingga kerjasama antar profesi kesehatan amat vital dalam menyelamatkan ibu melahirkan."

(Dokter - 2)

"Jika terjadi masalah pada saat akan melahirkan, sudah rapat antara tetua di keluarga lama sekali, setelah diputuskan yak, harus dibawa ke rumah sakit, ternyata speedboatnya nggak ada supirnya atau mobilnya habis bensinnya. Apakah Jampersal mendukung sampai pada biaya dan kesiapan transportasi? Saya kira kok tidak."

(Dokter - 3)
"KBnya apa? Ya itu, KB setelah Jampersal ini idealnya ya IUD. Tapi tidak semua sudah ikut KB. Kalaupun ikut, kebanyakan KB-nya Suntik atau Pil. Bukankah prediksi kontinyuitasnya rendah sekali?Kalau nantinya justru lebih banyak yang hamil dan hamil lagi, maka AKB atau AKI ya belum tentu dapat ditekan."

(Dokter - 4)

"Saya sebenarnya agak ngeri dengan Jampersal ini. Memang tujuannya membantu saat hamil, melahirkan dan menyusui. Akan tetapi kalau KB atau Family Planning tidak ditekankan, dan bukan merupakan pesan utama, maka apa jadinya negara ini? Kalau anak nomor berapapun mendapat fasilitas Jampersal, Mau berapa besar lagi jumlah penduduk Indonesia?"

(Dokter - 5)

"Yah, seringkali klaim Jampersal lebih sering terlambat."

(Bidan - 2)

"Apa yang perlu ditingkatkan lagi? Tidak ada."

(Ibu Menyusui - 3)

Kutipan dengan pesan yang sama kami jumpai di seluruh wawancara dengan 15 orang Ibu Menyusui. Mereka tidak merasa perlu meningkatkan sesuatu pun dari adanya Jampersal. Hal ini kami kategorikan bahwa sebenarnya masyarakat belum mengerti benar akan tujuan dari asuransi kesehatan. Apabila masyarakat sudah mengetahui, tentunya akan banyak saran guna perbaikan sistem Jampersal yang kami terima dari mereka. Sampai akhir penelitian ini, tidak satupun saran atau masukan kami dapatkan dari Ibu Menyusui.

Dari hasil penelitian kualitatif, maka kami membuat suatu kesimpulan kualitatif seperti yang tergambar dari Figur 1. Kami membuat sebuah gambar semacam bentukan oval, seperti dua sisi mata uang; salah satu sisi adalah Jampersal dan sisi lainnya adalah pelatihan (PONED). Jampersal terbukti meningkatkan angka kunjungan Ibu Hamil, Melahirkan dan Menyusui ke Puskesmas, dengan demikian meningkatkan Pencatatan dan Pelaporan Data dan cakupan Jampersal cukup luas di keseluruhan Puskesmas di Ternate. 
Tabel 1. Cakupan Jampersal selama Agustus 2011- Agustus 2012 di 7 Puskesmas di Pulau Ternate

\begin{tabular}{|c|c|c|c|c|c|c|c|c|c|c|c|}
\hline \multirow[t]{2}{*}{$\begin{array}{c}\text { Nama } \\
\text { Puskesmas }\end{array}$} & \multirow{2}{*}{\multicolumn{2}{|c|}{ AKB AKI }} & \multirow{2}{*}{$\begin{array}{c}\text { Kun- } \\
\text { jungan } \\
\text { ANC } \\
\text { ke-4 } \\
(\%)\end{array}$} & \multirow{2}{*}{$\begin{array}{c}\text { Kun- } \\
\text { jungan } \\
\text { Neonatus } \\
\text { ke } \\
\text { Puskes- } \\
\text { mas }(\%)\end{array}$} & \multirow[t]{2}{*}{ BBLR } & \multicolumn{2}{|c|}{$\begin{array}{c}\text { Jumlah } \\
\text { persalinan yang } \\
\text { ditolong Nakes }\end{array}$} & \multirow{2}{*}{$\begin{array}{c}\text { Yang } \\
\text { ditolong } \\
\text { Dukun } \\
\text { Bayi }\end{array}$} & \multirow{2}{*}{$\begin{array}{c}\text { Diberi- } \\
\text { kan } \\
\text { tablet } \\
\text { Fe }(\%)\end{array}$} & \multirow[t]{2}{*}{$\begin{array}{c}\text { Melaku- } \\
\text { kan KB } \\
(\%)\end{array}$} & \multirow{2}{*}{$\begin{array}{c}\text { Jumlah } \\
\text { Persa- } \\
\text { linan } \\
\text { Total }\end{array}$} \\
\hline & & & & & & Dokter & Bidan & & & & \\
\hline SIKO & 4 & 1 & 97 & 96 & 4 & 9 & 33 & Tidak & 99 & 100 & Tidak \\
\hline KALUMPANG & 3 & 0 & 97 & 96 & 4 & 4 & 21 & Diketahui & 96 & 0.9 & Diketahui \\
\hline KOTA & 3 & 1 & 97 & 99 & 0 & 2 & 21 & & 100 & 97 & \\
\hline KALUMATA & 6 & 2 & 94 & 91 & 7 & 3 & 26 & & 93 & 72 & \\
\hline GAMBESI & 1 & 1 & 85 & 68 & 7 & 4 & 12 & & 98 & 8.8 & \\
\hline SULAMANDHA & 3 & 0 & 83 & 97 & 5 & 4 & 31 & & 88 & 0.7 & \\
\hline MOTI & 5 & 0 & 100 & 100 & 0 & 3 & 10 & & 100 & 37 & \\
\hline
\end{tabular}

Meskipun demikian ada hal-hal yang memerlukan perhatian khusus yaitu: Klaim yang jangan terlalu berbelit, Sustainability kesehatan Ibu dan Anak melalui KB yang ideal, yaitu IUD, dukungan Jampersal untuk transportasi, fasilitas di Puskesmas dan di tempat rujukan dan untuk meningkatkan kuantitas dan kualitas PONED.

PONED sebagai sisi koin satunya sebaiknya ditingkatkan lagi tidak hanya masalah emergensi obstetrik, tetapi juga kemampuan berdialog dengan masyarakat dan pengertian akan budaya mereka untuk prosesproses pengambilan keputusan klinis (terkait budaya hirarki sosial, keputusan klinik yang berorientasi pada keputusan komunitas, kebiasaan penggunaan obat-obat tradisional dan bahasa non-verbal orang asia yang amat kental). Selain itu perlu digalakkannya Desa Siaga, dimana transportasi dan kesiapan transport pada saat yang diperlukan merupakan tanggung jawab seluruh warga (community empowerment), kemampuan tenaga kesehatan memberikan edukasi dan konseling terkait kasus-kasus Bumil Risti, misalnya Bumil sudah berada di tempat yang dekat dengan Rumah Sakit dikehamilan sebelum 36 minggu, pendampingan Bumil Risti oleh Bidan dan Dokter Umum, Kerjasama antar Tenaga Kesehatan demi keselamatan pasien dan Sosialisasi tujuan utama Asuransi Kesehatan seperti Jampersal sehingga masyarakat yang memahami benar tentunya akan mampu memberikan masukan yang sesuai guna peningkatan pelayanan kesehatan di masa mendatang. Seluruh hal yang tersebut di atas seyogyanya merupakan bagian dari PONED yang dapat difasilitasi oleh Jampersal.

\section{PEMBAHASAN}

Dalam bahasa Indonesia, tidak dikenal kata asuransi, yang ada adalah kata "jaminan" atau "tanggungan". Kata asuransi berasal dari bahasa Inggris insurance, yang berarti "memastikan". Pengertian asuransi adalah memastikan seseorang yang menderita sakit akan mendapatkan pelayanan kesehatan tanpa harus mempertimbangkan kemampuan keuangannya. Pihak yang menjamin biaya perawatan atau pengobatan disebut insurer. Dengan demikian Asuransi merupakan jawaban atas sifat ketidak-pastian dari kebutuhan pelayanan kesehatan. Asuransi yang baik akan menjamin sejak sebelum sakit, masa sakit sampai dengan proses rehabilitasi. Untuk memastikan bahwa kebutuhan pelayanan kesehatan dapat dibiayai secara memadai, maka seseorang atau kelompok kecil orang melakukan transfer risiko kepada pihak lain yang disebut insurer, ataupun badan penyelenggara jaminan.

Dari penjelasan mengenai asuransi di atas, jelas kita ketahui bahwa tertanggung mestinya memberikan transfer-resiko kepada penyelenggara asuransi. Dalam arti, masyarakat yang mendapatkan Jampersal, mestinya memahami sepenuhnya bahwa mereka juga harus memberikan sedikit dari peng- 
hasilannya untuk asuransi tersebut. Bisa dari pajak, ataupun bentuk lain. Dengan demikian masyarakat bukan hanya pasif-receiver saja, namun mereka juga berpartisipasi aktif terhadap adanya asuransi.

Ada jenis asuransi sosial yaitu asuransi yang diselenggarakan atau diatur oleh pemerintah yang melindungi golongan ekonomi lemah dan menjamin keadilan yang merata (equity). Suatu asuransi sosial didasarkan pada suatu undang-undang dengan pembayaran premi dan paket jaminan yang memungkinkan terjadinya pemerataan. Asuransi sosial beciri (1) kepesertaan wajib bagi sekelompok atau seluruh penduduk, (2) besaran premi ditetapkan oleh undang-undang, umumnya proporsional terhadap pendapatan/gaji, dan (3) paketnya ditetapkan sama untuk semua golongan pendapatan, yang biasanya sesuai dengan kebutuhan medis (Thabrany, 1999).

Klaim Jampersal yang seringkali terlambat yang ditemukan dalam penelitian ini, kemungkinan disebabkan karena ketergantungan biaya yang sepenuhnya ditanggung pemerintah. Hal ini bukan merupakan bentuk asuransi maupun pelayanan kesehatan yang ideal. Apabila diteruskan dengan sistem yang seadanya, maka dampak ke depannya masyarakat bisa jadi malas menjaga kesehatannya, malas melakukan $\mathrm{KB}$, sehingga masalah kesehatan terkait Kesehatan Reproduksi justru makin besar dan bukannya tertanggulangi seperti cita-cita Jampersal.

Perlakuan Jampersal yang tidak seimbang terhadap masyarakat pengguna asuransi dan terhadap tenaga kesehatan tercermin dari hasil wawancara pada mereka. Kelompok ibu menyusui sebanyak 15 orang sama sekali tidak dapat memberikan masukan yang bermakna terkait dengan Jampersal. Hal ini merupakan ketidak-wajaran, sebab sebagai pengguna pelayanan kesehatan, mestinya mereka memiliki banyak saran maupun masukan untuk peningkatan kualitas pelayanan kesehatan selanjutnya. Ketidakmampuan Ibu Menyusui memberikan saran bisa dikarenakan beberapa hal: 1. Bahwa mereka tidak memahami peran serta mereka dalam proses asuransi Jampersal, 2. Bahwa mereka bukan pengambil keputusan klinik apabila terjadi masalah dengan kesehatan mereka selama ada dukungan Jampersal, 3. Proses pelayanan kesehatan yang sudah sempurna oleh karena Jampersal. Akan tetapi tentunya poin no 3 diatas bukan merupakan pilihan karena tidak mungkin kesempurnaan dicapai hanya dengan 1 tahun pelaksanaan Jampersal.

Sebaliknya, Nakes mengutarakan banyak sekali hal-hal yang masih dapat ditingkatkan dari Jampersal terutama karena Dokter Umum merasa kurang diberdayakan dan Dokter Obgyn merasa rujukan selalu saja terlambat sehingga penanganan di rumah sakit tidak optimal. Para Dokter merasa peran sertanya dalam menangani kesehatan Repoduksi ini masih sangat minimal, ataupun merasa harus melakukan apapun demi keselamatan pasien, tidak peduli dengan honorarium yang akan diterima apakah dari Jampersal atau yang lain. Dengan kata lain, Dokter Umum tidak puas dengan fungsinya yang pasif sementara mereka me-rasa punya pengetahuan yang memadai untuk membantu menurunkan AKB dan AKI, sedangkan Dokter Obgyn merasa apapun yang ia lakukan untuk menolong persalinan biasanya sudah terlambat. Kerjasama antar profesi kesehatan belum tercermin secara baik, meskipun sudah diberlakukan Jamper-sal.

Selain itu, Jampersal ternyata masih menutup mata terhadap berbagai masalah terkait dengan Kesehatan Reproduksi seperti masalah sosialisasi fungsi asuransi, masalah transportasi dan masalah peningkatan kualitas training Nakes, semacam PONED. Di Belanda, asuransi kesehatan mencakup biaya transportasi seperti ambulance, juga biaya yang dibutuhkan terkait pelayanan kesehatan yang diperlukan misalnya fisioterapi (Holland Ministry of Health, Welfare and Sport. 2012). Di daerah terpencil seperti Ternate, dimana speedboat maupun mobil yang tentunya siap siaga dengan bensin dan sopir, sudah semestinya mendapat dukungan Jampersal. Hal ini sudah semestinya pula termasuk dalam usaha sosialisasi fungsi asuransi kesehatan yang dilakukan oleh Jampersal.

Selain itu, asuransi yang baik juga belum tentu menjamin menurunnya target 
MDGs, dalam hal ini adalah AKB dan AKI. Pelatihan dalam hal ini PONED akan amat sangat signifikan dalam menanggulangi AKB dan AKI. Keterampilan Nakes, Kerjasama Nakes demi keselamatan pasien adalah isu utama. Asuransi negara federal di Amerika Serikat: Medicare, memberikan bantuan biaya bagi training /pendidikan lanjutan bagi Nakes (Brown, 2012). Nakes yang terlatih dengan baik akan meningkatkan kualitas pelayanan kesehatan (termasuk menurunkan angka mortalitas), meningkatkan kepuasan pasien dan dengan demikian akan menghemat biaya kesehatan (Starfield, 1994, Starfield et al, dan 2005, World Health Organization. 2012).

Dua sisi mata uang yang kami gambarkan sebagai hasil penelitian kualitatif adalah dikarenakan tidak terdapatnya hubungan antara pelatihan lanjutan bagi Nakes tentang PONED dan system pembiayaan, dalam penelitian ini. Asuransi yang ideal akan membantu pendidikan berkelanjutan Nakes karena menyadari bahwa tanpa Nakes yang terampil, kualitas pelayanan kesehatan tidak mungkin tercapai dan biaya kesehatan tidak dapat ditekan. Asuransi yang ideal akan memikirkan bagaimana membagi berbagai pembiayaan menjadi suatu hal yang efektif yang tujuan akhirnya sebenarnya akan membantu menurunkan biaya kesehatan itu sendiri. Jampersal sama sekali jauh dari sebuah sistem asuransi yang ideal. Apabila ada

\section{DAFTAR RUJUKAN}

Brown D. 2012.Graduate Medical Education: Medicare support provides vital funding to train our doctors and maintain patient access. University of California.

Crowl TK. 1996. Fundamentals of Educational Research. New York: McGraw-Hill.

Finlay and Ballinger. 2006. Qualitative Research for Allied Health Professionals. West Sussex: John Willey and Sons.

Holland Ministry of Health, Welfare and Sport. 2012. The Netherlands Insurance.The Haque.

Permenkes RI. 2011. Petunjuk Teknis Pelaksanaan Jaminan Persalinan. Jakarta : Kemenkes RI

Starfield B, Shi L, Machinko J. 2005. Contribution of Primary Care to Health System and Health. The Milbank Quarterlyv, Vol. 83, No. 3: 457-502 sistem pembiayaan yang ideal, maka gambar dua sisi mata uang yang ditemukan dalam penelitian ini dapat dimungkinkan untuk berubah menjadi gambar payung; dengan asuransi sebagai payungnya, melindungi seluruh pihak penyelenggara pelayanan kesehatan dan penggunanya.

\section{KESIMPULAN}

Manfaat satu tahun pelaksanaan Jampersal di Pulau Ternate belum optimum. Berbagai bidang pelayanan kesehatan masih memerlukan dukungan sistem asuransi yang mendekati ideal, yaitu : Pertama, perlunya sosialisasi fungsi asuransi di mana pengguna asuransi semestinya bukan pasif-receiver melainkan juga terlibat aktif dalam proses penguatan asuransi. Kedua, masalah transportasi yang mendasari proses rujukan di daerah terpencil seperti Ternate perlu diantisipasi. Ketiga, masalah pelatihan tenaga kesehatan yang lebih komprehensif dan berkualitas, tidak hanya terbatas pada PONED tetapi mencakup pemahaman budaya, konseling dan kerjasama antar petugas kesehatan perlu dilakukan. Keempat, Perlunya peningkatan $\mathrm{k}$ ualitas kesehatan reproduksi melalui Keluarga Berencana yang ideal; seperti IUD, akan membantu menekan Angka Kematian Bayi (AKB) dan Angka Kematian Ibu (AKI), jumlah penduduk Indonesia dan status kesehatan rakyat Indonesia secara umum.

Starfield B. 1994. Is primary care essential? The Lancet, Vol 344; 1129-1133

Thabrany, H. 1999. Introduksi Asuransi Kesehatan. Yayasan Penerbit Ikatan Dokter Indonesia, Jakarta.

Thabrany, H. 2001. Asuransi Kesehatan di Indonesia. Depok: Pusat Kajian Ekonomi Kesehatan, FKMUI

WHO. 2008. Primary Health Care, Now More Than Ever. Jenewa : WHO

World Health Organization. 2012. Primary Health Care: Now More Than Ever. Geneva: WHO Report 